\title{
Protective effect of Coriandrum sativum extract against inflammation and apoptosis in liver ischaemia/reperfusion injury
}

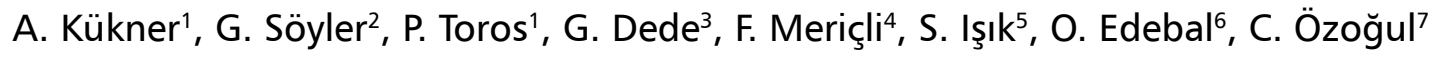 \\ ${ }^{1}$ Department of Histology and Embryology, Faculty of Medicine, Near East University, Nicosia, Cyprus \\ ${ }^{2}$ Koç University, Graduate School of Health Sciences and School of Medicine, Istanbul, Turkey \\ ${ }^{3}$ Department of Histology and Embryology, Faculty of Medicine, Abant Izzet Baysal University, Bolu, Turkey \\ ${ }^{4}$ Department of Phytotherapy, Faculty of Pharmacy, Near East University, Nicosia, Cyprus \\ ${ }^{5}$ Department of Analytic Chemistry, Faculty of Pharmacy, Near East University, Nicosia, Cyprus \\ ${ }^{6}$ Department of Biochemistry, Medical Hospital, Near East University, Nicosia, Cyprus \\ 'Department of Histology and Embryology, Faculty of Medicine, Girne University, Kyrenia, Cyprus
}

[Received: 6 April 2020; Accepted: 13 May 2020]

Background: The aim of this study was to investigate the anti-inflammatory and antioxidant effects of Coriandrum sativum extract on liver ischaemia reperfusion injury at light microscopic and biochemical levels.

Materials and methods: Sham, ischaemia/reperfusion injury (IRI), IRI + Coriandrum sativum extract and only Coriandrum sativum extract groups were formed. Sixty minutes of ischaemia and 60 minutes of reperfusion were performed. In the treatment group, $300 \mathrm{mg} / \mathrm{kg} / \mathrm{day}$ Coriandrum sativum was given by gavage. Hepatic tissues were fixed in $4 \%$ paraformaldehyde. Serum alanine aminotransferase (ALT), aspartate aminotransferase (AST) and alkaline phosphatase (ALP) enzymes were measured. Nuclear factor-kappa beta (NF-KB), tumour necrosis factor-alpha (TNF- $\alpha$ ) and caspase-3 immunohistochemistry staining was performed. Microscopic scoring was performed in terms of sinusoidal congestion, vacuolisation, and necrosis.

Results: Sinusoidal enlargement and diffuse congestion, Kupffer cell increase, neutrophil increase in necrotic areas, vacuolisation in hepatocytes, and bile duct proliferation in the portal triad were observed in ischaemia/reperfusion hepatic tissue. Very rare, necrotic areas were observed in the Coriandrum sativum treatment group, while congestion and vacuolisation and bile duct proliferation were decreased compared to the ischaemic group. The AST and ALT levels were increased in the $I R I$ and $I R I+C o r i a n d r u m$ sativum groups. When compared to the IRI group, the AST and ALT levels of the Coriandrum sativum were considerably decreased. The $I R I$ and $I R I+$ Coriandrum sativum groups had statistically significant differences in ALP compared to that of the Coriandrum sativum and Sham groups. There was no significant difference between the ALP levels of the $I R I$ and $I R I+$ Coriandrum sativum groups TNF- $\alpha, N F-\kappa B$ and caspase-3 immune positive stained hepatocytes were numerous and widely observed in the injury group. There were positive TNF- $\alpha$ immunohistochemical staining Kupffer cells in the IRI group. In the group treated with Coriandrum sativum, Kupffer cells were

Address for correspondence: Prof. A. Kükner, MD, Near East University, Medicine Faculty, Histology and Embryology Department, 99138, Nicosia, Cyprus, tel: +90 5338734460 (Mobile); +90 392675 1000, ext 3012 (Office), e-mail: akukner@hotmail.com

This article is available in open access under Creative Common Attribution-Non-Commercial-No Derivatives 4.0 International (CC BY-NC-ND 4.0) license, allowing to download articles and share them with others as long as they credit the authors and the publisher, but without permission to change them in any way or use them commercially. 
not stained, while TNF- $\alpha, N F-\kappa B$ and caspase-3 expressing hepatocytes were found to be decreased compared to the IRI group. When the expression values of the $T N F-\alpha, N F-\kappa B$ and caspase-3 groups were evaluated statistically, it was seen that there was a significant decrease in the group treated with Coriandrum sativum. Conclusions: It was found that Coriandrum sativum extract decreased proinflammatory cytokine TNF- $\alpha$ and apoptotic cell death and liver enzymes in liver ischaemia/reperfusion injury. (Folia Morphol 2021; 80, 2: 363-371)

Key words: liver ischaemia, Coriandrum sativum, nuclear factor-kappa beta, tumour necrosis factor-alpha, caspase-3

\section{INTRODUCTION}

Liver ischaemia/reperfusion injury (IRI) is a clinical problem that increases morbidity and mortality after trauma, hepatectomy or liver transplantation $[13,14]$. The ischaemic period is described as a blockage of oxygen and nutrient transportations which, in turn, obstructs the cellular metabolism. Once the blood supply is restored by reperfusion, the sudden increase in the blood flow to the tissue increases the concentration of the free oxygen radicals and results in inflammatory cell infiltration at the site of the damage $[14,22]$. The acute phase of the reperfusion lasts between three to 6 hours. During this time, T-cell and Kupffer cell activation as well as the activation of adhesion molecules are increased. The late (subacute) phase is 18 to $24^{\text {th }} \mathrm{h}$ of reperfusion, and neutrophil infiltration reaches its peak level during this time. The activated Kupffer cells and other hepatic cells also initiate secretion of inflammatory mediators, such as tumour necrosis factor-alpha (TNF- $\alpha$ ), interleukin 6 (IL-6), increasing the expression levels of intercellular adhesion molecule (ICAM), vascular cell adhesion protein (VCAM) and P-selectins [10, 27]. TNF- $\alpha$ expression is regulated by nuclear factor kappa beta (NF-KB). NF-KB is a transcription factor that plays an important role in liver ischaemia reperfusion damage, inflammation response, and the protection and regeneration of hepatocytes [33]. Hepatic apoptosis is directly proportional to the severity of IRI $[5,6]$. Necrotic cell death in hepatic cells with apoptosis may also occur [35]. The pathophysiology of IRI has numerous determinative factors and it is essential to understand and identify these factors to develop new therapeutic strategies in preventive medicine [14]. Coriandrum sativum is an important medicinal plant that originated in the Eastern Mediterranean and subsequently spread to India, China and is now cultivated all over the world. Coriandrum sativum is frequently used in medicines, natural treatment, and the food preservative industry $[16,18,26,29]$. To the best of the authors' knowledge, this is the first study to extensively investigate the biochemical and anti-inflammation and antiapoptotic effects of Coriandrum sativum use on hepatic ischaemia reperfusion in a rat model. The aim of this study was to investigate the biochemical and microscopic effects of methanol extract of Coriandrum sativum on liver ischaemic reperfusion injuries in rats.

\section{MATERIALS AND METHODS}

Plant material and extraction

Leaves of Coriandrum sativum were collected from the Alayköy region in North Cyprus and then dried. Dried leaves were extracted with methanol using the maceration method and the extract was evaporated. According to the HPLC analysis (realised using Agilent Technologies 1200 series HPLC and separated with Eclipse XDB-C18 column, $150 \mathrm{~mm} \times 4.6 \mathrm{~mm}, 5 \mu \mathrm{m}$ ). As mobile phases, $(A)$ : water with $0.5 \%$ formic acid and (B): methanol were used at a flow rate of $1 \mathrm{~mL}$ $/ \mathrm{min}$. The gradient was initially $90-70 \%$ A for $18 \mathrm{~min}$, then $55-80 \%$ A for $5 \mathrm{~min}$ and finally, $90 \%$ A for $5 \mathrm{~min}$. The detection wavelength was set at $254 \mathrm{~nm}$. The injection volume was $10 \mu \mathrm{L}$ for each sample and standard solutions, and according to the results of data validation, the percentage of isoquercitrin was found to contain 139.25 ppm (0.21\%).

\section{Animals and experimental design}

All experimental protocols were performed according to the Guide for Care and Use of Laboratory Animals and were approved by the Animal Care and Use Local Ethics Committee of Near East University (2019/01-57). Six-seven months female Wistar Albino rats (450-500 $\mathrm{g}$ weight) were housed at a constant room temperature $\left(22 \pm 2^{\circ} \mathrm{C}\right)$ under a 12 -h 
light/dark cycle. They were fed standard rat chow $(210 \mathrm{kcal} / 100 \mathrm{~g} /$ day) and drank tap water ad libitum. All surgical interventions were performed between 9:00 am and 12:00 pm to minimise diurnal effects.

Animals were randomly divided into four groups:

- Sham group ( $n=10)$ : A midline incision was made, and the hepatic pedicle (contains ductus hepaticus, hepatic portal vein and proper hepatic artery) was mobilised. No blood supply blocked;

- Ischaemia/reperfusion injury (IRI) group $(n=10)$ : Ischaemia was achieved by clamping the hepatic pedicle with a vascular clamp for 1 hour after the ischaemic period, the clamp was opened and 1 hour reperfusion of the liver was provided;

- IRI + Coriandrum sativum group $(n=10)$ : Coriandrum sativum extract was given by gavage $300 \mathrm{mg} / \mathrm{kg} /$ day for 3 days before ischaemia and 1 hour before ischaemia [24];

- Coriandrum sativum group $(n=10)$ : Coriandrum sativum extract was given by gavage $300 \mathrm{mg} / \mathrm{kg} /$ /day for 3 days.

\section{Ischaemia/reperfusion}

All animals were given ketamine $\mathrm{HCl} 90 \mathrm{mg} / \mathrm{kg}$ (Ketalar R, Pfizer Drug Company, Istanbul, Turkey) + xylazine hydrochloride $10 \mathrm{mg} / \mathrm{kg}$ (Rompun $\mathrm{R}$ $23.32 \mathrm{mg} / \mathrm{mL}$, Bayer Drug Company, Istanbul, Turkey) after 15 hours fasting. The animals were placed on the operating table in the supine position, immobilised at four points, and a midline abdominal laparotomy was performed to expose the abdominal cavity. Hepatic IRI was performed by Pringle manoeuvre. After detaching of liver from the ligaments and hepatic pedicle (ductus hepaticus, hepatic portal vein and proper hepatic artery) was clamped with an atraumatic microvascular clamp and hepatic ischaemia in the lobus hepatis mediana and lobus hepatis sinister. After 60 minutes of ischaemia, the clamp was removed and $1 \mathrm{~mL} \mathrm{NaCl} 0.9 \%$ was administered intraperitoneally, then the abdomen was closed and we waited 1 hour for reperfusion [2]. The other hepatic lobs had taken whole portal and arterial blood supply. Colour change appeared in the ischaemic lobes; however, the colour of the lobes returned to normal in reperfusion. Rats were kept on heated tables during ischaemia and reperfusion. In IRI and IRI + Coriandrum sativum groups, rats were under anaesthesia for 60 minutes with reperfusion duration and no substance was given. At the end of the reperfusion period, blood was taken from the hearts of the rats and euthanased with the exsanguination method. Tissue samples were taken from the reperfused lobus hepatis sinister for histological examinations. Rats in Sham and Coriandrum sativum groups were euthanased by the same method and tissue samples were taken from lobus hepatis sinister. During the reperfusion period, 3 rats from the IRI group and 2 rats from the IRI + Coriandrum sativum group died.

\section{Blood sample analyses}

Serum alanine aminotransferase (ALT), aspartate aminotransferase (AST) and alkaline phosphatase (ALP) measurements were made by using an Abbott Architect $c 8000$ clinical chemistry analyser (Abbott Instruments-Abbott Diagnostics, Abbott Park, IL, A.B.D.).

\section{Light microscopy}

All rats were euthanased, and tissue samples were fixed in paraformaldehyde $4 \%$ for 48 hours, embedded in paraffin, and cut into $5 \mu \mathrm{m}$ sections. Haematoxylin and eosin staining was carried out to assess the general structure of the liver. Tissue sections were examined, with 10 fields per section, and scored from 0 to 4 for vacuolisation, sinusoidal congestion, and hepatocyte necrosis, which were evaluated semi-quantitatively according to the modified Suzuki scoring system [32].

\section{Immunohistochemical staining}

Immunohistochemical evaluation of the hepatic tissue samples were performed by the following stains: caspase-3 (anti-caspase-3 antibody, ab 2302, Abcam), TNF- $\alpha$ (anti-TNF- $\alpha$ antibody, ab183896, Abcam), NF-kB p65 (anti-NF-kB p65 antibody, ChIP Grade ab7970, Abcam). The cells stained positively with caspase-3, TNF- $\alpha$ and NF- $\mathrm{BB}$ were counted in a light microscope with a magnification of $40 \times$ in 20 different areas.

\section{Statistical analyses}

All the statistical analyses were performed with SPSS 17.0. Data obtained from the groups were compared using the non-parametric Kruskal-Wallis test within each group, whereas the groups were compared with each other using the Mann-Whitney $U$ test. A value of $p<0.05$ was considered to be statistically significant. 
Table 1. The mean values of liver enzymes in groups

\begin{tabular}{lccc}
\hline & ALT & AST & ALP \\
\hline Sham & $36.33 \pm 10.19^{\mathrm{a}}$ & $74.00 \pm 14.93^{\mathrm{a}}$ & $46.50 \pm 10.21$ \\
Coriandrum sativum & $39.33 \pm 3.77^{\mathrm{b}}$ & $73.17 \pm 17.75^{\mathrm{b}}$ & $54.50 \pm 9.57$ \\
IRI & $1297.50 \pm 357.30^{\mathrm{c}}$ & $1127.83 \pm 177.09^{\mathrm{c}}$ & $71.67 \pm 22.38^{\mathrm{a}}$ \\
IRI + Coriandrum sativum & $801.83 \pm 241.86^{\mathrm{c}}$ & $765.17 \pm 242.87^{\mathrm{c}}$ & $66.33 \pm 14.71^{\mathrm{a}}$ \\
P value & $0.000^{*}$ & $0.000^{*}$ & $0.048^{*}$ \\
\hline
\end{tabular}

*Kruskal-Wallis test significant value $\mathrm{p}<0.05$; abc Significance according to Mann-Whitney U test $(\mathrm{p}<0.05)$; aSignificance between Sham group and IRI, IRI + Coriandrum sativum; ${ }^{\mathrm{b} S}$ Significance between Coriandrum sativum group and IRI, IRI + Coriandrum sativum; ' ${ }^{\circ}$ Significance between IRI group and IRI + Coriandrum sativum; IRI — ischaemia/reperfusion injury; ALT — alanine aminotransferase; AST — aspartate aminotransferase; ALP — alkaline phosphatase

Table 2. Injury scoring in groups

\begin{tabular}{lccc}
\hline & Congestion & Vacuolisation & Necrosis \\
\hline Sham & $0.00 \pm 0.00^{\mathrm{a}}$ & $0.00 \pm 0.00^{\mathrm{a}}$ & $0.00 \pm 0.00^{\mathrm{a}}$ \\
Coriandrum sativum & $0.17 \pm 0.41^{\mathrm{b}}$ & $0.00 \pm 0.00^{\mathrm{b}}$ & $0.00 \pm 0.00^{\mathrm{b}}$ \\
$\mathrm{IRI}$ & $2.33 \pm 0.82^{\mathrm{abc}}$ & $1.50 \pm 0.55^{\mathrm{abc}}$ & $0.67 \pm 0.52^{\mathrm{abc}}$ \\
$\mid \mathrm{RI}+$ Coriandrum sativum & $0.83 \pm 0.75^{\mathrm{c}}$ & $0.33 \pm 0.52^{\mathrm{c}}$ & $0.17 \pm 0.41^{\mathrm{c}}$ \\
Pvalue & $0.001^{*}$ & $0.000^{*}$ & $0.000^{*}$ \\
\hline
\end{tabular}

${ }^{*}$ Kruskal-Wallis test significant value $\mathrm{p}<0.05$; abc Significance according to Mann-Whitney $\mathrm{U}$ test $(\mathrm{p}<0.05)$; aSignificance between Sham group and IRI group; ${ }^{\mathrm{b}}$ Significance between Coriandrum sativum group and IRI group; 'Significance between IRI + Coriandrum sativum and IRI group; IRI — ischaemia/reperfusion injury

\section{RESULTS}

\section{Biochemical results}

The AST and ALT levels were increased in the IRI and IRI + Coriandrum sativum groups. When compared to the IRI group, the AST and ALT levels of the Coriandrum sativum were considerably decreased. The IRI and IRI + Coriandrum sativum groups had statistically significant differences in ALP compared to that of the Coriandrum sativum and Sham groups. There was no significant difference between the ALP levels of the IRI and IRI + Coriandrum sativum groups (Table 1 ).

\section{Light microscopic results}

Congestion, vacuolisation, and necrosis were observed to be considerably higher in the IRI group when compared with the results of the Sham and Coriandrum sativum groups. The IRI + Coriandrum sativum group showed decreased congestion, vacuolisation, and necrosis. Nevertheless, the levels were still higher than those of the Sham and IRI groups (Table 2). Compared to the Sham group (Fig. 1A), dilatation and congestion of sinusoids (Fig. 1B), increased number of Kupffer cells (Fig. 1C), necrotic areas with hepatocyte degeneration and increased number of neutrophils (Fig. 1D), vacuolisation of hepatocytes especially around the portal triads (Fig. 1E), and proliferation of the bile ducts (Fig. 1F) were confirmed in the IRI group. The IRI + Coriandrum sa- tivum group showed decreased congestion (Fig. 1G), decreased Kupffer cell activation and, although lessened, a still discernible proliferation of the bile ducts (Fig. 1H). TNF- $\alpha, N F-\kappa B$ and caspase-3 expressions were very common and there was strong expression in hepatocytes in the IRI group compared to the sham groups. It was observed that there was no TNF- $\alpha, \mathrm{NF}-\kappa \mathrm{B}$ and caspase- 3 immunohistochemical staining in the liver sham group (Fig. 2A), but there were positive TNF- $\alpha$ immunohistochemical staining Kupffer cells (Fig. 2B) and hepatocytes (Fig. 2C) in the IRI group. In the group treated with Coriandrum sativum, Kupffer cells were not stained, while TNF- $\alpha$ expressing hepatocytes were found to be decreased compared to the IRI group (Fig. 2D). It was found that there was NF- $\mathrm{BB}$ staining in the IRI group (Fig. 2E). The severity of immunohistochemical staining and number of stained cells decreased in the group treated with Coriandrum sativum (Fig. 2F). It was observed that many hepatocytes were expressed caspase-3 in the IRI group (Fig. 2G), and the caspase- 3 expression was very low in the Coriandrum sativum treatment group (Fig. $2 \mathrm{H}$ ). When the expression values of the TNF- $\alpha, N F-\kappa B$ and caspase-3 groups were evaluated statistically, it was seen that there was a significant decrease in the group treated with Coriandrum sativum, in which the expressions increased in the IRI group. These results were positive correlated with the microscopic findings (Table 3). 

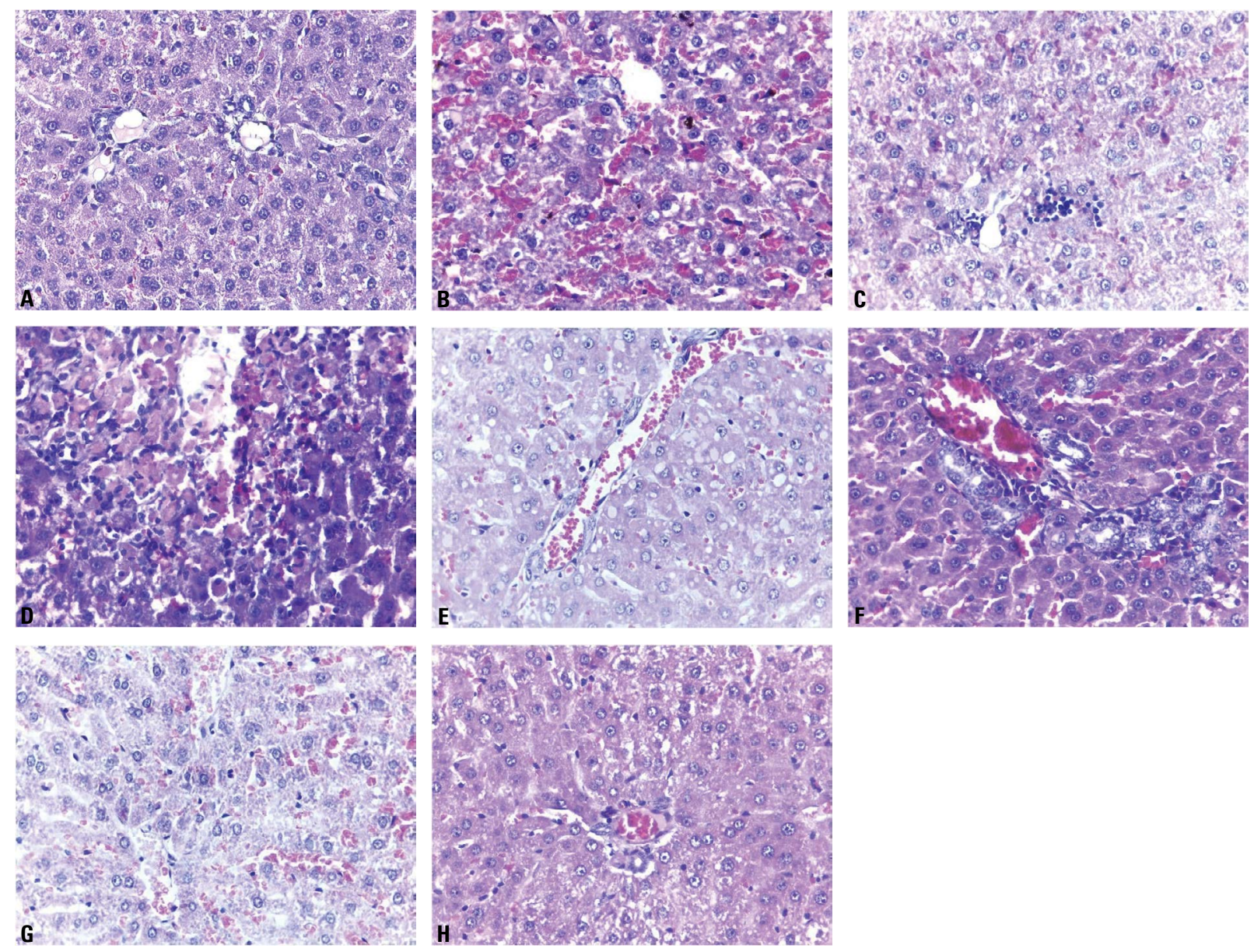

Figure 1. Liver tissue in experimental groups. A. Sham group. Dilatation of sinusoids, congestion (B), increased Kupffer cells (C), necrotic area and increased neutrophil number (D), vacuolisation in hepatocytes around the portal triads (E) and bile duct proliferation are observed in ischaemia/reperfusion injury (IRI) group (F). Congestion is less common than IRI group, when vacuolisation is not common (G), and bile duct proliferation continues to exist in portal triads as decreased $(\mathbf{H})$ in Coriandrum sativum treated IRI group. Haematoxylin and eosin $\times 40$.

\section{DISCUSSION}

The results obtained throughout this study indicate that Coriandrum sativum has therapeutic effects on the histological and biochemical outcomes of liver IRI during the acute phase. During liver transplantations or surgeries, IRI can have a negative impact on regeneration. Many different factors can trigger this, and one of them is the duration of the ischaemic period [3]. The preventive or therapeutic effects of various plant extracts or components in IRI have been studied. The blockage of endothelial adhesion molecules, reduction of cytokines is released from cells, free oxygen radicals and hepatocyte apoptosis have been discussed [1]. The Coriandrum sativum plant has antioxidant and anti-inflammatory effects and the protective effect of Coriandrum sativum on liver damage caused by various hepatotoxic substances has been reported [20, 21, 24, 30]. Studies have shown that Coriandrum sativum extract dosage is not toxic up to $3000 \mathrm{mg} / \mathrm{kg}$ [25]. In our study, we have identified the anti-inflammatory effect of $\mathrm{Co}$ riandrum sativum sourced from the Cyprus-Nicosia region at low doses in rats treated with $300 \mathrm{mg} / \mathrm{kg}$. It has been determined that Coriandrum savitum extract obtained from this region contains $139.25 \mathrm{ppm}$ isoquercitrin as the active substance. Isoquercitrin (quercetin-3-O- $\beta$-d-glucopyranoside) is a one of the major glycosidic form of quercetin and founds commonly in many medicinal plants. It has antioxidant, anti-inflammatory, antiapoptotic effects [17]. It is the major bioactive component of the Coriander (Coriandrum sativum L.) and it is commonly found in coriander leaves and roots. In recent years, isoquercitrin has a great potential due to the discovery of new biological activities and its ability to be obtained by enzymatic modification of rutin [34].

Upon reperfusion injury during the first few hours, Kupffer cells are activated and they release cytokines. 

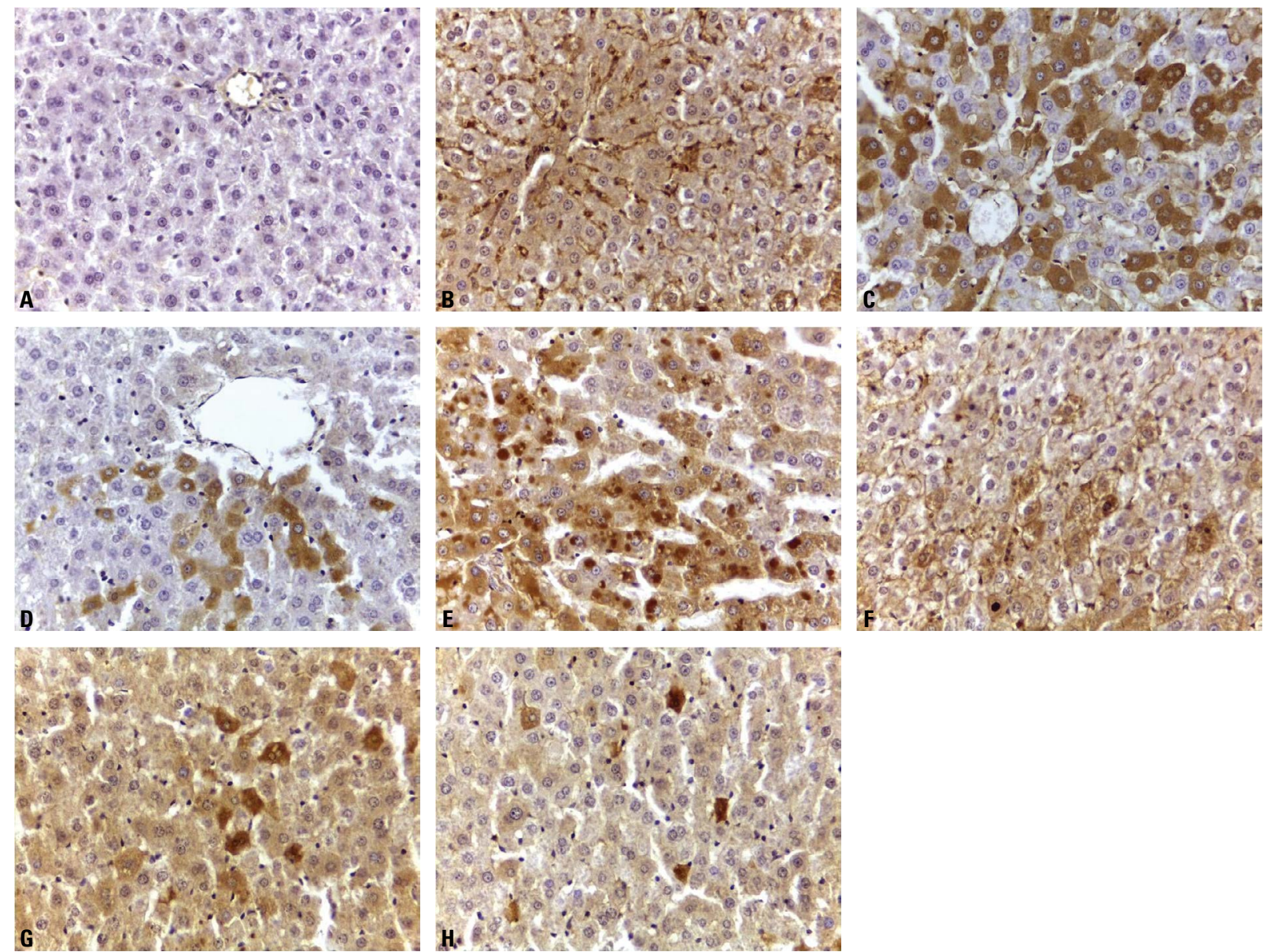

Figure 2. Tumour necrosis factor-alpha (TNF- $\alpha$ ), nuclear factor-kappa beta (NF- $\kappa \mathrm{B}$ ) and caspase-3 were negative in the immunohistochemical stained liver tissue belonging to Sham group (A). It appears to be TNF- $\alpha$ positive in Kupffer cells (B) and hepatocytes (C) in the ischaemia/reperfusion injury (IRI) group. In the Coriandrum sativum treated IRI group, there is no staining in Kupffer cells and it is observed that hepatocytes expressing TNF- $\alpha$ are decreased compared to IRI group (D). Commonly in hepatocytes NF- $\mathrm{KB}$ expression appears to be positive in the IRI group (E). The severity of NF- $\kappa B$ immunohistochemical staining and the number of stained cells decreased in the Coriandrum sativum treated IRI group (F). Caspase-3 is expressed in a large number of hepatocytes in the IRI group (G), it is seen that the number of immune positive hepatocytes decreased in the Coriandrum sativum treated IRI group (H). TNF- $\alpha$, NF- $\mathrm{KB}$ and caspase- 3 immunohistochemistry staining $\times 40$.

Table 3. Nuclear factor-kappa beta (NF- $\kappa \mathrm{B})$, tumour necrosis factor-alpha (TNF- $\alpha$ ) and caspase-3 expression in groups

\begin{tabular}{|c|c|c|c|}
\hline & TNF- $\alpha$ & NF- $\kappa$ B & Caspase-3 \\
\hline Sham & $0.05 \pm 0.21^{\mathrm{ab}}$ & $0.00 \pm 0.00^{a b}$ & $0.00 \pm 0.00^{\mathrm{ab}}$ \\
\hline Coriandrum sativum & $0.10 \pm 0.31^{c d}$ & $0.10 \pm 0.31^{\mathrm{cd}}$ & $0.05 \pm 0.22^{\text {cd }}$ \\
\hline$|\mathrm{R}|$ & $11.05 \pm 2.82^{a c}$ & $10.45 \pm 3.35^{a c}$ & $5.30 \pm 2.60^{\mathrm{ac}}$ \\
\hline IRI + Coriandrum sativum & $2.65 \pm 1.76^{\text {bde }}$ & $5.20 \pm 2.59^{\text {bde }}$ & $1.35 \pm 0.49^{\text {bde }}$ \\
\hline$P$ value & $0.000^{*}$ & $0.000^{*}$ & $0.000^{*}$ \\
\hline
\end{tabular}

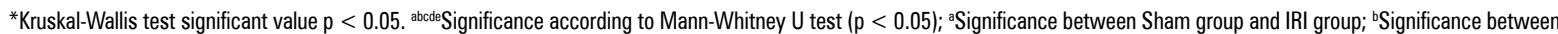
Sham group and IRI + Coriandrum sativum group; ' Significance between Coriandrum sativum group and IRI group; dSignificance between Coriandrum sativum group and IRI + Coriandrum sativum group; eSignificance between IRI group and IRI + Coriandrum sativum group; IRI — ischaemia/reperfusion injury

There is a positive correlation between Kupffer cell activation and liver IRI $[9,11]$. On the other hand, neutrophils play the main role in the stimulation process of the inflammatory cascade mechanisms [7]. During reperfusion, selectin receptors on the endothelial cells increase in number; leukocytes adhere to the endothelial cells and then migrate to the site of the injury [9, 22]. Nuclear pyknosis of hepatocytes, scattering of the hepatic cords and hepatic sinusoid dilation can be observed. It was observed that diffuse local necrosis in reperfusion, vacuolisation in hepatocytes and inflammatory cell increase were significantly 
increased; these findings decreased on the $3^{\text {rd }}$ day and decreased to the minimal level on the $7^{\text {th }}$ day [9]. Although the cause of hepatocyte fats due to IRI is not fully understood, may be multifactorial and involve both parenchymal and nonparenchymal dysfunction, a large amount of lipid accumulation occurs in hepatocytes due to metabolic changes in ischaemia during the reperfusion stage. Intracellular triglycerides accumulate due to deterioration of hepatocyte metabolism and vacuolisation is observed on a light microscope [28]. The presence of steatosis is associated with an increased mortality risk between $2 \%$ and $14 \%$, following liver resection surgery [19].

In our study, congestion of sinusoids was very prominent and widespread in the IRI group. Areas of necrosis were not common but numerous necrotic hepatocytes and vacuolisation were detected. Bile duct proliferation in portal areas was detected as a result of ligation of the bile duct in the hepatic pedicle. In the IRI + Coriandrum sativum group, there were a few mitotic hepatocytes around the portal area. Kupffer cell activation was observed in fewer areas. Decrease in the Kupffer cells affected metabolic changes and the necrotic hepatocyte count. In addition, the decreased vacuolisation due to lipid accumulation in the hepatocytes in the treatment group depends on the hypolipidaemic effect of Coriandrum sativum.

Tumour necrosis factor-alpha is the primary inflammatory cytokine secreted from Kupffer cells in ischaemia/reperfusion injuries. TNF- $\alpha$ and NF-kB levels increase significantly in the reperfusion stage after ischaemia. Excessive increase of TNF- $\alpha$ activity in ischaemia and reperfusion injuries stimulates cell death or apoptosis by direct toxic effects on the mitochondria $[8,36]$. NF- $\mathrm{KB}$ is thought to act as a proinflammatory. Therefore, inhibition of NF-KB is expected to suppress the inflammatory response $[15,27]$. The expression of NF- $\mathrm{kB}$ was seen in the hepatocyte cytoplasm after warm ischaemia $\left(35-37^{\circ} \mathrm{C}\right)$; there was no nuclear staining [15]. Our study results are compatible with the literature. A positive correlation was observed between increased TNF- $\alpha$ expression and increased NF- $\mathrm{KB}$ expression in the IRI group. In IRI group, the increase in neutrophils is very evident. It was determined that inflammation markers and inflammation decreased in the group treated with Coriandrum sativum. In the Coriandrum sativum group, NF- $\mathrm{KB}$ reduction was significantly detected in hepatocytes and Kupffer cells due to decreased TNF- $\alpha$ expression. As our experimental model is a warm ischaemia model,
$\mathrm{NF}-\mathrm{KB}$ staining was seen in hepatocyte cytoplasm. In addition to inflammation in liver ischaemia reperfusion injuries, apoptotic cell death and necrosis are observed in hepatocytes [4, 12]. In our study, both necrotic and apoptotic cell death were observed. It was determined that the number of apoptotic and necrotic cells decreased in the Coriandrum sativum treatment group, and this was due to decreased neutrophil caused by the anti-inflammatory effect of Coriandrum sativum.

In ischaemia/reperfusion studies, AST and ALT values increased in IRI $[23,24,31]$. AST and ALT levels were significantly increased in the ischaemic group and decreased in the Coriandrum sativum treated group but did not reach the control level in our study. In the ALP level, no significant difference was observed between IRI and IRI + Coriandrum sativum groups. One of the main causes of the ALP increase is bile duct obstruction and proliferation. While bile duct proliferation was common in portal triads in IRI, proliferation was found to be less in the IRI + Coriandrum sativum group. This result explained the high ALP level.

There is a complex series of complicated events involving parenchymal and non-parenchymal cells in hepatic IR injuries resulting from trauma, cancer surgery, and transplantation. The levels of TNF- $\alpha$ and NF- $\mathrm{KB}$, inflammatory factors, increase and NF- $\kappa B$ causes an increase in inflammation-associated cell adhesion molecules, cytokines, anti-apoptotic and pro-apoptotic proteins. Therefore, it is very important to prevent inflammation to prevent and/or reduce ischaemia reperfusion damage. Our aim, in this study, was to investigate the possible protective effect of Coriandrum sativum against hepatic IRI-induced inflammation, oxidative stress, apoptosis, and hyperlipidaemia in the hepatic tissue. In the acute phase, $300 \mathrm{mg} / \mathrm{kg}$ Coriandrum sativum was used to reduce the damage, decrease liver enzymes, inflammation, and apoptosis. The hepatoprotective effect of Coriandrum sativum could be partly due to inhibition of the expression of pro-inflammatory cytokines. Anti-inflammatory and anti-apoptotic effect of Coriandrum sativum was demonstrated immunohistochemically. In addition, lipid accumulation in the hepatocytes of the group treated with Coriandrum sativum, vacuolisation decreased. This finding was an indication of the anti-lipidaemic effect of Coriandrum sativum. Isoquercetin, the active ingredient in Coriandrum sativum extract, is thought to play an important role. According 
to the literature review, no previous study has used Coriandrum sativum against liver ischaemia reperfusion injuries. To the best of the authors' knowledge, this is the first time such data has been provided.

\section{Limitations of the study}

The limitation of the study is the absence of oxidative stress data. Also, showing protein expressions with Western blotting method will strengthen our study results. Increasing the dose used and prolonged use before ischaemia, prolonging the reperfusion period and continuing Coriandrum sativum use will provide more effective results. Study of the effects of Coriandrum sativum on other cytokines at a molecular level will increase the knowledge on this subject. These study results will be the source of the studies to be done with Coriandrum sativum. In particular, the antioxidant effect of a certain amount of Coriandrum sativum consumed in daily life will prevent or delay the emergence of some diseases.

\section{CONCLUSIONS}

It was found that Coriandrum sativum extract decreased proinflammatory cytokine TNF- $\alpha$, apoptotic cell death and liver enzymes in liver ischaemia/ /reperfusion injury.

\section{REFERENCES}

1. Aćimović M, Milić N. Perspectives of the apiaceae hepatoprotective effects: a review. Nat Prod Commun. 2017; 12(2): 1934578X1701200, doi: 10.1177/1934578x1701200241.

2. Barlas AM, Kismet K, Erel S, et al. Erdosteine ameliorates the harmful effects of ischemia-reperfusion injury on the liver of rats. Acta Cir Bras. 2017; 32(10): 796-806, doi: 10.1590/s0102865020170100000001 , indexed in Pubmed: 29160366.

3. Casillas-Ramírez A, Mosbah IB, Ramalho F, et al. Past and future approaches to ischemia-reperfusion lesion associated with liver transplantation. Life Sci. 2006; 79(20): 1881-1894, doi: 10.1016/j.lfs.2006.06.024, indexed in Pubmed: 16828807.

4. Chattopadhyay P, Shukla G, Wahi AK. Protective effect of L-arginine against necrosis and apoptosis induced by experimental ischemic and reperfusion in rat liver. Saudi J Gastroenterol. 2009; 15(3): 156-162, doi: 10.4103/13193767.45356, indexed in Pubmed: 19636175.

5. Ge Y, Zhang Q, Li H, et al. Adipose-derived stem cells alleviate liver apoptosis induced by ischemia-reperfusion and laparoscopic hepatectomy in swine. Sci Rep. 2018; 8(1): 16878, doi: 10.1038/s41598-018-34939-x, indexed in Pubmed: 30442976.

6. Go KL, Lee S, Zendejas I, et al. Mitochondrial dysfunction and autophagy in hepatic ischemia/reperfusion injury. Biomed Res Int. 2015; 2015: 183469, doi: 10.1155/2015/183469, indexed in Pubmed: 26770970.
7. Honda M, Takeichi T, Asonuma K, et al. Intravital imaging of neutrophil recruitment in hepatic ischemia-reperfusion injury in mice. Transplantation. 2013; 95(4): 551-558, doi: 10.1097/TP.0b013e31827d62b5, indexed in Pubmed: 23423266.

8. limuro $Y$, Nishiura T, Hellerbrand $C$, et al. NFkappaB prevents apoptosis and liver dysfunction during liver regeneration. J Clin Invest. 1998; 101(4): 802-811, doi: 10.1172/ $\mathrm{JCl} 483$, indexed in Pubmed: 9466975.

9. Jaeschke H, Farhood A. Neutrophil and Kupffer cell-induced oxidant stress and ischemia-reperfusion injury in rat liver. Am J Physiol. 1991; 260(3 Pt 1): G355-G362, doi: 10.1152/ ajpgi.1991.260.3.G355, indexed in Pubmed: 2003603.

10. Jaeschke $H$, Hasegawa T. Role of neutrophils in acute inflammatory liver injury. Liver Int. 2006; 26(8): 912-919, doi: 10.1111/j.1478-3231.2006.01327.x, indexed in Pubmed: 16953830 .

11. Jaeschke H. Mechanisms of Liver Injury. II. Mechanisms of neutrophil-induced liver cell injury during hepatic ischemia-reperfusion and other acute inflammatory conditions. Am J Physiol Gastrointest Liver Physiol. 2006; 290(6): G1083-G1088, doi: 10.1152/ajpgi.00568.2005, indexed in Pubmed: 16687579.

12. Jiang $X$, Kuang Ge, Gong $X$, et al. Glycyrrhetinic acid pretreatment attenuates liver ischemia/reperfusion injury via inhibiting TLR4 signaling cascade in mice. Int Immunopharmacol. 2019; 76: 105870, doi: 10.1016/j. intimp.2019.105870, indexed in Pubmed: 31493667.

13. Jiménez-Castro MB, Cornide-Petronio ME, Gracia-Sancho J, et al. Inflammasome-Mediated inflammation in liver ischemia-reperfusion injury. Cells. 2019; 8(10), doi: 10.3390/ cells8101131, indexed in Pubmed: 31547621.

14. Konishi T, Lentsch AB. Hepatic ischemia/reperfusion: mechanisms of tissue injury, repair, and regeneration. Gene Expr. 2017; 17(4): 277-287, doi: 10.3727/105221617X150427 50874156, indexed in Pubmed: 28893351.

15. Kuboki S, Schuster R, Blanchard J, et al. Role of heat shock protein 70 in hepatic ischemia-reperfusion injury in mice. Am J Physiol Gastrointest Liver Physiol. 2007; 292(4): G1141-G1149, doi: 10.1152/ajpgi.00491.2006.

16. Laribi B, Kouki K, M'Hamdi M, et al. Coriander (Coriandrum sativum L.) and its bioactive constituents. Fitoterapia. 2015; 103: 9-26, doi: 10.1016/j.fitote.2015.03.012, indexed in Pubmed: 25776008.

17. Liang $S, X u Z$, Ruan $Y$, et al. Isoquercitrin attenuates renal ischemia/reperfusion injury through antioxidation, anti-inflammation, and antiapoptosis in mice. Transplant Proc. 2020; 52(3): 1014-1019, doi: 10.1016/j.transproceed.2019.12.038, indexed in Pubmed: 32115238.

18. Mandal S, Mandal M. Coriander (Coriandrum sativum L.) essential oil: Chemistry and biological activity. Asian Pac J Trop Biomed. 2015; 5(6): 421-428, doi: 10.1016/j. apjtb.2015.04.001.

19. McCormack L, Petrowsky H, Jochum W, et al. Hepatic steatosis is a risk factor for postoperative complications after major hepatectomy: a matched case-control study. Ann Surg. 2007; 245(6): 923-930, doi: 10.1097/01. sla.0000251747.80025.b7, indexed in Pubmed: 17522518.

20. Moustafa AH, Ali EM, Moselhey SS, et al. Effect of coriander on thioacetamide-induced hepatotoxicity in rats. Toxicol Ind Health. 2014; 30(7): 621-629, doi: 
10.1177/0748233712462470, indexed in Pubmed: 23042592.

21. Nishio R, Tamano H, Morioka H, et al. Intake of heated leaf extract of coriandrum sativum contributes to resistance to oxidative stress via decreases in heavy metal concentrations in the kidney. Plant Foods Hum Nutr. 2019; 74(2): 204-209, doi: 10.1007/s11130-019-00720-2, indexed in Pubmed: 30783906.

22. Oliveira TH, Marques PE, Proost $P$, et al. Neutrophils: a cornerstone of liver ischemia and reperfusion injury. Lab Invest. 2018; 98(1): 51-62, doi: 10.1038/ labinvest.2017.90, indexed in Pubmed: 28920945.

23. Osman AS, Osman AH, Kamel MM. Study of the protective effect of ischemic and pharmacological preconditioning on hepatic ischemic reperfusion injury induced in rats. JGH Open. 2017; 1(3): 105-111, doi: 10.1002/jgh3.12018, indexed in Pubmed: 30483545.

24. Pandey A, Bigoniya P, Raj V, et al. Pharmacological screening of Coriandrum sativum Linn. for hepatoprotective activity. J Pharm Bioallied Sci. 2011; 3(3): 435-441, doi: 10.4103/0975-7406.84462, indexed in Pubmed: 21966166.

25. Patel D, Desai $S$, Devkar R, et al. Acute and sub-chronic toxicological evaluation of hydro-methanolic extract of Coriandrum sativum L. seeds. EXCLI J. 2012; 11: 566-575, indexed in Pubmed: 27847445.

26. Prachayasittikul V, Prachayasittikul S, Ruchirawat S, et al. Coriander (Coriandrum sativum): A promising functional food toward the well-being. Food Res Int. 2018; 105 : 305-323, doi: 10.1016/j.foodres.2017.11.019, indexed in Pubmed: 29433220.

27. Quesnelle KM, Bystrom PV, Toledo-Pereyra LH. Molecular responses to ischemia and reperfusion in the liver. Arch Toxicol. 2015; 89(5): 651-657, doi: 10.1007/s00204-0141437-x, indexed in Pubmed: 25566829.

28. Schleicher J, Dahmen U. Computational modeling of oxidative stress in fatty livers elucidates the underlying mechanism of the increased susceptibility to ischemia/ /reperfusion injury. Comput Struct Biotechnol J. 2018; 16: 511-522, doi: 10.1016/j.csbj.2018.10.013, indexed in Pubmed: 30505404.
29. Silva F, Domingues FC. Antimicrobial activity of coriander oil and its effectiveness as food preservative. Crit Rev Food Sci Nutr. 2017; 57(1): 35-47, doi: 10.1080/10408398.2013.847818, indexed in Pubmed: 25831119.

30. Sreelatha S, Padma PR, Umadevi M. Protective effects of Coriandrum sativum extracts on carbon tetrachloride-induced hepatotoxicity in rats. Food Chem Toxicol. 2009; 47(4): 702-708, doi: 10.1016/j.fct.2008.12.022, indexed in Pubmed: 19146910.

31. Sun $L, W u$ Q, Nie $Y$, et al. A role for MK2 in enhancing neutrophil-derived ROS production and aggravating liver ischemia/reperfusion injury. Front Immunol. 2018; 9: 2610, doi: 10.3389/fimmu.2018.02610, indexed in Pubmed: 30483268.

32. Suzuki S, Toledo-Pereyra LH, Rodriguez FJ, et al. Neutrophil infiltration as an important factor in liver ischemia and reperfusion injury. Modulating effects of FK506 and cyclosporine. Transplantation. 1993; 55(6): 1265-1272, doi: 10.1097/00007890-199306000-00011, indexed in Pubmed: 7685932.

33. Uchinami $H$, Yamamoto $Y$, Kume $M$, et al. Effect of heat shock preconditioning on NF-kappaB/l-kappaB pathway during $\mathrm{I} / \mathrm{R}$ injury of the rat liver. Am J Physiol Gastrointest Liver Physiol. 2002; 282(6): G962-G971, doi: 10.1152/ ajpgi.00466.2001, indexed in Pubmed: 12016121.

34. Wang J, Sun GX, Yu L, et al. Enhancement of the selective enzymatic biotransformation of rutin to isoquercitrin using an ionic liquid as a co-solvent. Bioresour Technol. 2013; 128: 156-163, doi: 10.1016/j.biortech.2012.10.098, indexed in Pubmed: 23201508.

35. Yang M, Antoine DJ, Weemhoff JL, et al. Biomarkers distinguish apoptotic and necrotic cell death during hepatic ischemia/reperfusion injury in mice. Liver Transpl. 2014; 20(11): 1372-1382, doi: 10.1002/lt.23958, indexed in Pubmed: 25046819.

36. Zapolska-Downar D, Naruszewicz M. Propionate reduces the cytokine-induced VCAM-1 and ICAM-1 expression by inhibiting nuclear factor-kappa B (NF-kappa B) activation. J Physiol Pharmacol. 2009; 60(123): 131, indexed in Pubmed: 19617655. 